\title{
Alelopatia de acículas de Pinus taeda na germinação e no desenvolvimento de plântulas de Avena strigosa
}

\author{
Allelopathic of Pinus taeda needles on the germination and development of Avena strigosa seedlings
}

\author{
Laércio Ricardo Sartor ${ }^{\mathrm{I}}$ Paulo Fernando Adami ${ }^{\mathrm{I}}$ Nelso Chini ${ }^{\mathrm{I}}$ Thomas Newton Martin $^{\mathrm{II}}$ \\ José Abramo Marchese ${ }^{\mathrm{I}}$ André Brugnara Soares ${ }^{\mathrm{I}}$
}

RESUMO

O trabalho teve por objetivo caracterizar o efeito alelopático do extrato aquoso de acículas de Pinus taeda na germinação e no desenvolvimento inicial de plântulas de aveia preta comum (Avena strigosa). $O$ experimento foi conduzido no Laboratório de Bioquímica e Fisiologia Vegetal da Universidade Tecnológica Federal do Paraná (UTFPR), Campus de Pato Branco, utilizando o delineamento inteiramente casualizado, com tratamento fatorial (bifatorial com parcela subdividida no tempo), com três repetições, sob condições de temperatura, umidade e luminosidade controladas. Os tratamentos foram compostos por cinco concentrações (0, 25, 50, 75 e 100\%) de extrato bruto de acículas de pínus em estágio vegetativo (acícula verde), moderadamente decomposto (acícula seca) e em decomposição avançada (acícula decomposta). As avaliações foram realizadas a cada 24 horas. Foram avaliados os parâmetros porcentagem de germinação, velocidade média de germinação e comprimento de radículas e epicótilos das plântulas de Avena strigosa. O estágio de acícula verde afetou significativamente as variáveis avaliadas e esse problema aumentou com a concentração do extrato.

Palavras-chave: aveia preta comum, alelopatia interespecífica, pínus, sistema silvipastoril.

\section{ABSTRACT}

The purpose of this study was to verify the allelopathic effect of aqueous extract from the Pinus taeda needles on the germination and development of black oat (Avena strigosa) seedlings. The work was carried out at the Plant Physiology and Biochemistry Laboratory at the Federal Technological University of Paraná (UTFPR), Campus Pato Branco, using a completely randomized design with factorial distribution in three replicates, under temperature, humidity and light controlled conditions. The extract from the pine needles was composed of five percentages $(0,25,50,75$ and $100 \%)$ from the crude extract (EB) dilution, composed of distilled water + pine needles in vegetative stage (green needles), moderately decomposed (dry needles) and in advanced decomposition (decomposed needles). The germination percentage, average speed of germination, the length of the primary roots and the length from the seedlings roots of Avena strigosa were evaluated. The stage of green needles affected the variables studied and showed linearly effect with the increasing concentration of the crude extract.

Key words: black oat, inter-specific allelopathy, pine, silvipastoral system.

\section{INTRODUÇÃO}

Alguns vegetais liberam produtos do seu metabolismo secundário que podem impedir ou estimular a germinação e/ou o desenvolvimento de outras plantas relativamente próximas, caracterizando um processo alelopático (SOARES, 2000). O efeito desses compostos pode ser mais ou menos pronunciado e é determinado pelas características de cada espécie e idade da planta, podendo ser exsudado pelas raízes, pela decomposição dos órgãos da planta (acículas) ou por meio de chuvas e causando lixiviação desses compostos do extrato superior das plantas para o solo (RICE, 1984). Além disso, outro fator é a potencialidade da planta em produzir esses compostos secundários ou de ser resistentes a esses exsudados, tanto no momento da germinação, quanto no desenvolvimento vegetativo.

IUniversidade Tecnológica Federal do Paraná (UTFPR), Campus Pato Branco, Pato Branco, PR, Brasil.

IIUTFPR, Campus Dois Vizinhos, CP 157, 85660-000, Dois Vizinhos, PR, Brasil. E-mail: thomas.martin@hotmail.com. Autor para correspondência. 
A alelopatia tem sido comumente definida como a capacidade dos vegetais superiores ou inferiores produzirem substâncias químicas, com ação direta ou indireta (estimuladora ou inibidora), que influencia o desenvolvimento da comunidade de plantas ou dos microorganismos devido às substâncias químicas liberadas no ambiente (GATTI et al., 2004; PERIOTTO et al., 2004; FRITZ et al., 2007). Essas substâncias pertencem a diferentes categorias de compostos, tais como fenóis, terpenos, alcalóides, poliacetilenos, ácidos graxos e peptídeos provenientes de diferentes órgãos, incluindo folhas, flores, frutos e gemas de muitas espécies vegetais (RICE, 1984). A manipulação de fatores relacionados com a ação alelopática pode ser explorada para a melhoria e o aumento da produção, no controle ambiental de plantas daninhas, pragas e doenças e na síntese de agrotóxicos naturais. A alelopatia pode ser apresentada como autoxicidade (ou alelopatia intraespecífica), na qual a planta produz compostos químicos que prejudicam a germinação e/ ou o desenvolvimento da própria espécie (CHON, 2004). Para a alelopatia intraespecífica, os extratos aquosos das raízes de alfafa não causaram inibição na germinação nem no comprimento das plântulas de alfafa. Além disso, os resultados sugerem variações intraespecíficas na tolerância aos compostos aleloquímicos e uma produção preferencial destes na parte aérea da planta de alfafa, material crioulo (PEREIRA et al., 2008). A outra forma de alelopatia é a interespecífica (indivíduos de espécies diferentes) (FERREIRA \& BORGHETTI, 2004). Dentre os exemplos de alelopatia interespecífica citados na literatura, destaca-se o extrato volátil de óleo de jaborandi (Pilocarpus microphyllus), o qual estimulou o crescimento de radículas e não inibiu a germinação de sementes de alface (ALVES et al., 2004), demonstrando efeito alelopático benéfico.

Os trabalhos referentes a efeitos alelopáticos de acículas de Pinus taeda sobre o crescimento e o desenvolvimento de plantas forrageiras são escassos, principalmente, no Brasil. Contudo, FERREIRA et al. (2007) realizaram um experimento com o objetivo de avaliar o efeito alelopático de extratos etanólicos de Eucalyptus citriodora Hook. e Pinus elliottii L. na germinação e no crescimento inicial de picão-preto e alface (Lactuca sativa L.) e constataram que o extrato etanólico de Pinus elliotti não demonstrou efeito alelopático sobre o picão e a alface, porém o extrato de Eucalypto citriodora reduziu a velocidade de germinação de picão-preto. Comparativamente, o picão-preto foi mais sensível que a alface sob efeito do etanóico de Eucalypto citriodora. Sendo assim, justifica-se o estudo do comportamento germinativo de sementes e o desenvolvimento de plântulas na presença do extrato de acículas de pínus. Dessa forma, o objetivo do presente trabalho foi verificar a existência de efeito alelopático de diferentes concentrações de extrato de acículas de Pinus taeda, em diferentes estágios, sob a germinação de sementes e o desenvolvimento de plântulas de Avena strigosa.

\section{MATERIAL E MÉTODOS}

O experimento foi desenvolvido no Laboratório de Bioquímica e Fisiologia Vegetal da Universidade Tecnológica Federal do Paraná (UTFPR), Campus de Pato Branco, sob condições de temperatura, umidade e luminosidades controladas. O substrato foi umedecido com água destilada e concentrações de extrato de acícula de Pinus taeda em diferentes estágios (um vegetativo e dois em estágios de decomposição). O delineamento experimental foi inteiramente casualizado, com os tratamentos em bifatorial (3 x 5 estágio da acícula de pínus versus concentração do extrato de acícula, respectivamente), em três repetições para Avena strigosa. As parcelas principais foram subdivididas no tempo, ou seja, as avaliações ocorreram às 24, 48, 72, 96, 120 e 144 horas da semeadura.

Os estágios das acículas, no momento da coleta, foram: vegetativo (AV), cujas acículas foram coletadas ainda verdes; moderadamente decompostas (AM), acículas coletadas em processo inicial de decomposição (aspecto seco, mas em pouca decomposição) e em decomposição avançada (AD), coletadas acículas em estágio avançado de decomposição acima do solo. As amostras foram coletadas em um mesmo reflorestamento de Pinus taeda com 10 anos de cultivo, na região sudoeste do Paraná, o clima é classificado como Cfb, segundo classificação de KÖPPEN (MORENO, 1961).

Para cada estágio, foram realizadas diferentes concentrações de extratos de acículas, em que, para a obtenção do extrato bruto, foram triturados $125 \mathrm{~g}$ de acículas $\mathrm{AV}, 12,5 \mathrm{~g}$ de $\mathrm{AM}$ e $40 \mathrm{~g}$ de $\mathrm{AD}$, com 42,5\%, 84,79\% e 52,6\% de massa seca, respectivamente, em 500mL de água destilada, por meio de um liquidificador, durante cinco minutos, com posterior repouso por mais 10 minutos. Depois de filtrado, o extrato líquido foi centrifugado durante cinco minutos a 3.000rpm, e foi extraído o líquido sobrenadante, o qual compôs o extrato bruto (EB), concentração de $100 \%$ da concentração água + extrato de acículas. A partir do EB, foram feitas diluições com água destilada para alcançar as concentrações de 0, 25, 50, 75 e 100\% do $\mathrm{EB}$, por meio da equação $\mathrm{C}_{1} * \mathrm{~V}_{\mathrm{i}}=\mathrm{C}_{2} * \mathrm{~V}_{\mathrm{f}}$, ou seja, $\mathrm{V}_{\mathrm{i}}=$

Ciência Rural, v.39, n.6, set, 2009. 
$\left(\mathrm{C}_{2} * \mathrm{~V}_{\mathrm{f}}\right) / \mathrm{C}_{1}$, sendo $\mathrm{V}_{\mathrm{i}}$ o volume do EB a ser adicionado na diluição, $\mathrm{C}_{1}$ a concentração do $\mathrm{EB}(100 \%), \mathrm{C}_{2}$ a concentração desejada e $\mathrm{V}_{\mathrm{f}}$ o volume final da solução $(100 \mathrm{~mL}$ ), em que 0 (zero) \% era a testemunha composta apenas por água destilada e 100\% era o EB puro extraído após centrifugação.

As caixas plásticas utilizadas foram tipo gerbox, com dimensões de 15 x $15 \mathrm{~cm}$, com tampa, as quais constituíram as unidades experimentais. Como substrato, foram utilizadas três unidades de papel-filtro, e foram adicionados $5 \mathrm{~mL}$ de água destilada, inclusive no tratamento $0 \%$ de EB, para umedecer o papel-filtro, e $5 \mathrm{~mL}$ da solução proposta, conforme tratamento.

Após umedecer o papel-filtro com água destilada e antes de adicionar as soluções com extrato de acícula de pínus, em cada unidade experimental, foram distribuídas 25 sementes de Avena strigosa, em cinco linhas, com cinco unidades. As sementes foram submetidas ao teste de germinação no laboratório de sementes da UTFPR, Campus de Pato Branco, a fim de verificar o poder germinativo do lote utilizado, sendo esse valor de $80 \%$. As sementes foram desinfectadas com uma solução de hipoclorito de sódio a $2 \%$ por 15 minutos. Após a semeadura, as caixas gerbox foram fechadas com tampas próprias, e os filtros de papel foram mantidos úmidos com água destilada e, em seguida, deixadas em câmaras BOD reguladas sob temperatura de $20^{\circ} \mathrm{C}$ e fotoperíodo de 24 horas.

As avaliações foram realizadas no período de 24, 48, 72, 96, 120 e 144 horas após a semeadura e, conforme LABOURIAU \& VALADARES (1976), foram calculadas a porcentagem de germinação $(\mathrm{G})$, por meio da equação $G(\%)=(N / A) * 100$, em que $G$ é a porcentagem de germinação, $\mathrm{N}$ é o número de sementes germinadas e Aé o número total de sementes colocadas para germinar; o tempo médio de germinação $(\mathrm{t})$ por meio da equação $t=\left(\Sigma n_{i} * t_{i}\right) / \Sigma n_{i}$ sendo ni o número de sementes germinadas por dia e ti o tempo de incubação (horas); e a velocidade média de germinação(IVG), IVG = (1/t), em que t é o tempo médio de germinação. Foram realizadas avaliações biométricas, medindo o comprimento (mm) das raízes primárias e das plântulas, ou seja, a distância do colo da planta até o ápice meristemático do sistema radicular e da plântula (GATTI et al., 2004), com auxílio de uma régua milimetrada. Considerou-se germinada a semente com aproximadamente $0,1 \mathrm{~mm}$ de protrusão radicular, e as plântulas foram consideradas normais ou anormais, segundo as Regras para Análise de Sementes (BRASIL, 1992), considerando germinadas as sementes que originaram plântulas normais, com todas as estruturas essenciais perfeitas, demonstrando, assim, sua aptidão para produzirem plantas normais sob condições favoráveis de campo. Os resultados foram submetidos à análise de variância e a estudos de regressão, a 5\% de probabilidade de erro. Os resultados foram analisados pelo programa Statgraphicsplus 4.1.

\section{RESULTADOS E DISCUSSÃO}

Houve interação significativa entre os estágios de acícula de pínus versus tempo de avaliação para porcentagem de germinação de sementes de Avena strigosa. A porcentagem de germinação, no extrato de acícula verde, ajustou-se a uma equação linear, enquanto que, nos outros estágios de acícula de pínus, seca e decomposta, a porcentagem de germinação ajustou-se a equações quadráticas (Figura 1). Observase, conforme equações (Figura 1), que a germinação, no extrato aquoso de acícula verde, foi afetada consideravelmente, não ultrapassando valores de $37 \%$ (conforme equação) de germinabilidade após 144 horas. Quando foram utilizados os extratos aquosos de acícula moderadamente decomposta, obteve-se porcentagem máxima de germinação após 124 horas e, para as acículas decompostas, o valor máximo de germinação (77\%) ocorreu após 144 horas. Esse fato caracteriza-se pelo efeito alelopático inibitório pronunciado nas sementes de sementes de aveia submetidas a concentrações de extrato de acícula verde de Pinus taeda.

As menores percentagens de germinação foram observadas pela aplicação de acícula verde, que provavelmente possui compostos alelopático, já para acícula seca e em decomposição tais compostos já devem ter sido liberados ou transformados no solo. Não foi observada interação significativa entre estágio de acícula e concentração do extrato bruto para as variáveis analisadas.

O crescimento e desenvolvimento de alface foram inibidos por restos de Pinus radiata e Eucalyptus globulus, cujo efeito alelopático foi atribuído principalmente a compostos fenólicos (SOUTO et al., 1994). Os mesmos autores verificaram que a toxidade dos extratos foi maior nos primeiros estágios de decomposição, em função dos compostos fitotóxicos liberados, e a inibição por parte do material vegetativo não foi observada após seis meses de decomposição. Esses resultados são similares e corroboram os observados neste trabalho, em que foi verificada maior atividade alelopática nas acículas verdes.

A interação entre a concentração do extrato bruto de acícula versus o tempo de avaliação para porcentagem de germinação foi significativa $\left(P G=7,9604233-0,93978836 y+0,0068867725 y^{2}+\right.$ $1,3809458 \mathrm{x}-0,0051876653 \mathrm{x}^{2}, \mathrm{r}^{2}=0,88$ ), (y varia de $0 \mathrm{a}$ 


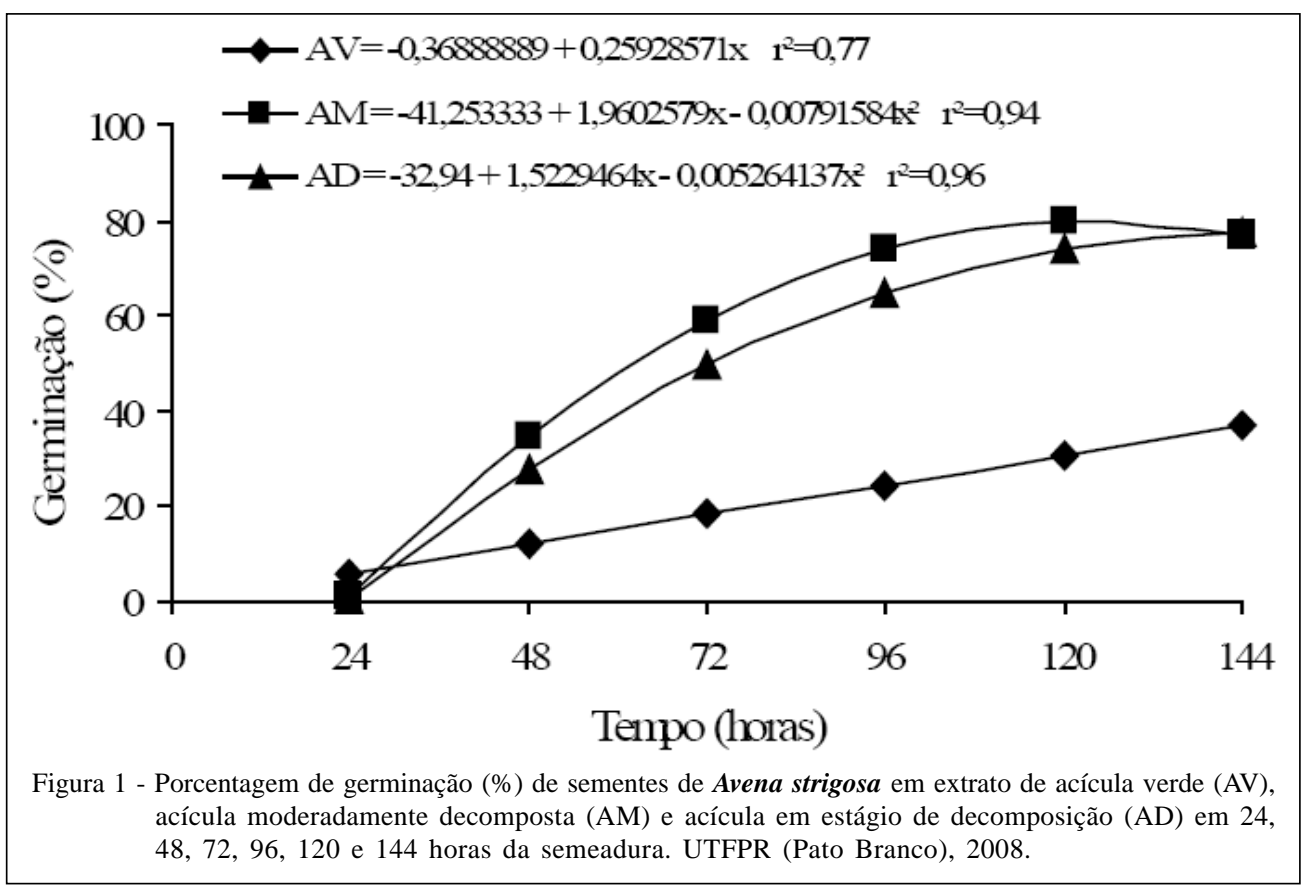

100, correspondente às concentrações e x de 0 a 144 referente ao tempo de avaliação). O efeito alelopático inibitório começou na concentração $25 \%$ de extrato bruto, especialmente de acícula verde, e foi mais pronunciado para 75 e $100 \%$ do extrato bruto para todas as variáveis. Tal efeito atrasou a germinação de sementes de Avena strigosa, e as menores percentagens de germinação foram verificadas nas maiores concentrações do extrato bruto de acícula de pínus, nos três estágios de decomposição estudados, com efeito considerável para estágio de acícula verde.

O tratamento que avaliou as acículas verdes apresentou 90\% de plântulas anormais para as sementes que germinaram, sendo desconsideradas como sementes germinadas. Algumas sementes germinaram com 144 horas, mas sem a capacidade de desenvolverse. O efeito alelopático inibitório diferenciado entre os estágios de acícula explica-se pelo fato de a acícula verde possuir maior concentração de substâncias que vieram a impedir a germinação das sementes e prejudicar seu desenvolvimento. Provavelmente, os compostos que antes estavam presentes nas acículas verdes e nas acículas decompostas foram liberados para o solo na decomposição, assim como indica RICE (1984) em seus estudos.

O efeito de extrato de acículas de Pinus halepensis em diferentes idades influencia a germinação de Lactuca sativa e Linum strictum, especialmente acículas de árvores mais velhas, efeito atribuído a compostos fenólicos (FERNANDEZ et al., 1996). Por outro lado, os resultados encontrados por FERREIRA et al. (2007) descrevem que o extrato etanólico de Pinus eliotti, em diferentes concentrações, não apresentaram efeito alelopático para as variáveis germinação e crescimento inicial, para o picão-preto e a alface, o que foi observado no presente trabalho para tratamentos com extrato de acícula seca e acícula decomposta. A diferença entre os dois resultados pode ser explicada pela magnitude da suscetibilidade das espécies testadas em relação ao extrato bruto.

Observou-se interação significativa para comprimento de radícula e de epicótilo entre estágio de acícula de pínus versus concentração do extrato bruto versus tempo de avaliação, e as equações referentes à superfície de resposta encontrada estão na tabela 1. Tanto para comprimento de radícula, quanto para comprimento de epicótilo, os efeitos negativos ao crescimento foram observados na presença de extrato aquoso de acícula verde de pínus. Os efeitos crescentes com maiores doses do extrato bruto causam, assim, uma inibição para o comprimento de radícula e epicótilo. Já na presença de extrato de acícula moderadamente decomposta e decomposta de pínus os resultados não mostram interferências no comprimento de radícula e epicótilo de plântulas de aveia preta e estas tiveram desenvolvimento normal.

Em alguns trabalhos, observou-se que o efeito alelopático não se limita apenas a inibir a germinação, mas também o retardamento da velocidade de germinação. Considerando apenas água destilada, 
Tabela 1 - Parâmetros das equações referentes ao desdobramento da interação: estágio de acícula de Pinus taeda versus tempo da semeadura (x variando de 0 a 144 horas) para a variável porcentagem de germinação (\%GER) e estágio de acícula de pínus versus concentração do extrato bruto versus tempo da semeadura para as variáveis comprimento de radícula e de epicótilo de Avena strigosa, sob extrato de acícula verde (AV), acícula moderadamente decomposta (AM) e acícula em estágio de decomposição (AD). UTFPR (Pato Branco), 2008.

\begin{tabular}{|c|c|c|c|}
\hline \multicolumn{4}{|c|}{ Porcentagem de germinação } \\
\hline & AV & $\mathrm{AM}$ & $\mathrm{AD}$ \\
\hline $\mathrm{a}$ & $-0,36888889$ & $-41,253333$ & $-32,94$ \\
\hline b & 0,25928571 & 1,9602579 & 1,5229464 \\
\hline c & & $-0,0079158399$ & $-0,0052641369$ \\
\hline $\mathrm{r}^{2}$ (ajustado) & 0,77 & 0,94 & 0,96 \\
\hline \multirow[t]{3}{*}{ Equação } & $\%$ GER $=\mathrm{a}+\mathrm{bx}$ & $\%$ GER $=\mathrm{a}+\mathrm{by}+\mathrm{cx}^{2}$ & $\%$ GER $=\mathrm{a}+\mathrm{bx}+\mathrm{cx}^{2}$ \\
\hline & ------------------------ & imento de Radícula*--- & ------------------------ \\
\hline & AV & $\mathrm{AM}$ & $\mathrm{AD}$ \\
\hline $\mathrm{a}$ & 0,62821714 & $-0,55547714$ & $-0,18806032$ \\
\hline $\mathrm{b}$ & $-0,028621905$ & 0,010554571 & 0,0019034921 \\
\hline c & 0,00019161905 & $-0,8144127 e-5$ & 1,9428571e-6 \\
\hline d & 0,0032839087 & 0,010848403 & 0,0028445437 \\
\hline $\mathrm{e}$ & 3,6958499e-5 & $8,1305804 \mathrm{e}-5$ & 0,00011762979 \\
\hline \multirow[t]{3}{*}{$\mathrm{r}^{2}$ (ajustado) } & 0,65 & 0,95 & 0,91 \\
\hline & -------------- & imento do Epicótilo*--- & 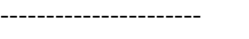 \\
\hline & AV & AM & $\mathrm{AD}$ \\
\hline $\mathrm{a}$ & 0,95180667 & 0,16677778 & 0,38301111 \\
\hline b & $-0,028817333$ & 0,0015448889 & 0,0007133333 \\
\hline c & 0,0001953778 & $-0,01589292$ & $-0,02395917$ \\
\hline d & $-0,015165804$ & 0,00018980471 & 0,00027365704 \\
\hline $\mathrm{e}$ & 0,0002255353 & 1,0751118e-6 & $7,1753008 \mathrm{e}-7$ \\
\hline $\mathrm{r}^{2}$ (ajustado) & 0,78 & 0,96 & 0,93 \\
\hline
\end{tabular}

*A equação é representada por $Z=a+b y+c y^{2}+d x+e x^{2}$, em que y varia de 0 a 100 (concentrações) e $\mathbf{x}$ de 0 a 144 (horas).

foram verificados maior germinação e maior desenvolvimento, em comparação com a presença do extrato de acícula verde de $\boldsymbol{P}$. taeda. A germinação das sementes e o desenvolvimento das plântulas foram afetados com o aumento da concentração do extrato bruto de acícula verde. Verificou-se interação significativa entre estágio de acícula de pínus versus concentração do extrato bruto para velocidade de germinação. A velocidade de germinação diminuiu com o aumento da concentração do extrato de acícula verde, observando-se uma equação linear decrescente $(G e r \%=0,0103086-0,0000623243 y$, em que $y=$ são as concentrações). Já a velocidade de germinação de sementes de Avena strigosa, em meio com extrato de acícula seca e acícula moderadamente decomposta de pínus, não se ajustou à equação de regressão e acompanhou os valores obtidos somente em água destilada. Com isso, confirma-se que, além de prejuízo na germinação, compostos presentes na acícula verde de pínus também reduzem a velocidade de germinação de Avena strigosa.
Os efeitos alelopáticos de canela-sassafrás (extratos aquosos de folhas, cascas de tronco e cascas de raízes) foram testados sobre a germinabilidade das sementes, o desenvolvimento do sistema radicular e da parte aérea, o teor de clorofila da parte aérea e a respiração das células radiculares de plântulas de sorgo por CARMO et al. (2007). Os autores verificaram que metabólitos secundários da canela-sassafrás causaram alterações metabólicas e morfológicas nas plantas de sorgo. Portanto, a presença de canela-sassafrás no ambiente pode desencadear efeitos similares sobre outras espécies vegetais na sua vizinhança.

Os resultados obtidos no presente estudo concordam com os resultados obtidos em outros estudos que verificam o efeito de diversas arbóreas sobre características de germinação, crescimento e desenvolvimento, como, por exemplo, no caso da sucupira-branca (Pterodon emarginatus), que, quando aplicado o extrato metanólico do tronco dessa planta, a $150 \mathrm{ppm}$, inibiu $83 \%$ do desenvolvimento da raiz, $75 \%$ da parte aérea e $30 \%$ da germinação de sementes de capim-colonião (Panicum maximum) (HERNÁNDEZ- 
TERRONES et al., 2007). Além disso, os resultados obtidos estão de acordo com os estudos realizados por SOUZA FILHO et al. (2006), os quais observaram que a espécie malícia se mostrou mais sensível aos efeitos alelopáticos dos extratos brutos e das partições, além do óleo essencial que inibiu a germinação da malícia e estimulou a germinação no mata-pasto. A atividade alelopática das substâncias químicas isoladas esteve associada à concentração, e a atividade mais intensa foi em 60ppm.

Sabe-se que a acícula, na maioria das vezes, se desprende da árvore já em estágio avançado de senescência. Abaixa produção de forragem em ambiente com a presença de acículas de pínus então pode ser justificada, considerando a alta relação carbono nitrogênio $(\mathrm{C}: \mathrm{N})$ das acículas de pínus. Essa característica pode interferir no processo de desenvolvimento e crescimento de plantas, quando o nitrogênio presente no solo é, em grande parte, usado pelos micro-organismos na decomposição das acículas, existindo certa competição por $\mathrm{N}$ entre a planta a ser cultiva nesse solo e os micro-organismos (processo de imobilização de N). Outra justificativa pode ser dada devido ao fator físico da presença da acícula moderadamente decomposta sobre as sementes ou plântulas, o que pode vir a ter prejudicado o stand de planta e, por consequência, diminuir a produção de forragem.

A produção de acículas em um reflorestamento de pínus, em idade já avançada, é grande e pode ser uma alternativa a ser usada como substrato na produção de mudas de espécies arbóreas, frutíferas e olerícolas ou mesmo como cobertura vegetal, especialmente, na área olerícola, com custo extremamente baixo, uma vez que não foi observado efeito alelopático no presente trabalho para estágios mais avançados de decomposição da acícula. Contudo, pode-se observar efeito alelopático com extrato de aquoso de acícula verde de pínus.

\section{CONCLUSÕES}

A germinação, o comprimento de radícula e de epicótilo e a velocidade de germinação de Avena strigosa são afetados quando cultivadas na presença de extrato aquoso de acícula verde de Pinus taeda, principalmente nas maiores concentrações do extrato. Extratos aquosos de acícula moderadamente decomposta e em decomposição avançada não afetam a germinação e o desenvolvimento de plântulas de Avena strigosa.

\section{REFERÊNCIAS}

ALVES, M.C.S. et al. Alelopatia de extratos voláteis na germinação de sementes e no comprimento da raiz de alface. Pesquisa Agropecuária Brasileira, v.39, n.11, p.10831086, 2004. Disponível em: <http://www.scielo.br/ scielo.php? script =sci_art text \& pid = S 0100 204X2004001100005>. Acesso em: 20 jan. 2009. Doi: 10.1590/S0100-204X2004001100005.

BRASIL. Regras para análise de sementes. Brasília: SNDA/ DNDV/CLAV, Ministério da Agricultura e Reforma Agrária, 1992. 365p.

CARMO, F.M.S. et al. Alelopatia de extratos aquosos de canelasassafrás (Ocotea odorifera (Vell.) Rohwer). Acta Botânica Brasiliense. v.21, n.3, p.697-705, 2007. Disponível em: $<$ http://www.scielo.br/scielo.php?pid=S 0102 33062007000300016\&script=sci_arttext $>$. Acesso em: 20 jan. 2009. Doi: 10.1590/S0102-33062007000300016.

CHON, S.U. Allelopathic and autotoxic effects of alfalfa plant and soil extracts. Korean Journal of Crop Science, v.49, n.1, p.7-11, 2004.

FERNANDEZ, C. et al. Potencial allelopathic effect of Pinus halepensis in the secondary succession: an experimental approach. Chemoecology, v.16, n.2, p.97-105, 1996.

FERREIRA, A.G.; BORGHETTI, F. Germinação do básico ao aplicado. Porto Alegre: ARTMED, 2004. 323p.

FERREIRA, M.C. et al. Potenciação alelopática de extratos vegetais na germinação e no crescimento inicial de picão preto e alface. Ciência e Agrotecnologia, v.31, n.4, p.1054-1060, 2007. Disponível em: $<$ http://www.scielo.br/scielo.php?script=sci_arttext\&pid=S1413$70542007000400017 \& \operatorname{lng}=$ en\&nrm=iso\&tlng=pt $>$. Acesso em: 20 jan. 2009. Doi: 10.1590/S1413-70542007000400017.

FRITZ, D. et al. Germination and growth inhibitory effects of Hypericum myrianthum and $H$. polyanthemum extracts on Lactuca sativa L. Revista Brasileira de Farmacognosia, v.17, n.1, p.44-48, 2007. Disponível em: <http://www.scielo.br/ scielo.php? script=s ci_art text \& pid=S 0102 $695 X 2007000100010 \& \operatorname{lng}=$ en $\& n r m=i s o \& \operatorname{lng}=e n>$. Acesso em: 20 jan. 2009. Doi: 10.1590/S0102-695X2007000100010.

GATTI, A.B. et al. Atividade alelopática de extratos aquosos de Aristolochia esperanzae $O$. Kuntze na germinação e no crescimento de Lactuca sativa L. e Raphanus sativus L. Acta Botanica Brasilica, v.18, n.3, p.459-472, 2004.

HERNÁNDEZ-TERRONES, M.G. et al. Estudo fitoquímico e alelopático do extrato de caule de sucupira-branca (Pterodon emarginatus). Planta Daninha, v.25, n.4, p.755-762, 2007. Disponível em: <http://www.scielo.br/scielo.php?pid=S010083582007000400012\&script=sci_arttext $>$. Acesso em: 20 jan. 2009. Doi: 10.1590/S0100-83582007000400012.

LABOURIAU, L.G.; VALADARES, M.B. On the germination of seeds of Calotropis procera. Anais da Academia Brasileira de Ciências, v.48, n.1, p.263-284, 1976.

MORENO, J.A. Clima do Rio Grande do Sul. Porto Alegre: Secretaria da Agricultura, 1961. 41p.

Ciência Rural, v.39, n.6, set, 2009. 
PEREIRA, F.B. et al. Alelopatia intra-específica de extratos aquosos de folhas e raízes de alfafa na germinação e no crescimento inicial de plântulas de dois materiais de alfafa: crioulo e melhorado. Ciência Rural, v.38, n.2, p. 561-564, 2008. Disponível em: $<$ ht t p: / / w w w. scielo.br/scielo.php?pid=S 0103 $84782008000200046 \&$ script $=$ sci_arttext\&tlng $=\mathrm{e}>$. Acesso em: 20 jan. 2009. Doi: 10.1590/S0103-84782008000200046.

PERIOTTO, F. et al. Efeito alelopático de Andira humilis Mart. Benth. na germinação e no crescimento de Lactuca sativa L. e Raphanus sativus L. Acta Botanica Brasilica, v.18, n.3, p.425-30, 2004. Disponível em: <http://www.scielo.br/ $\mathrm{s}$ c i e l $\mathrm{o}$. $33062004000300003 \&$ script $=$ sci_arttext\&tlng $=p t>$. Acesso em: 20 jan. 2009. Doi: 10.1590/S0102-33062004000300003.

RICE, E.L. Allelopathy. 2.ed. New York: Academic, 1984. 422p.
SOARES, G.L.G. Inibição da germinação e do crescimento radicular de alface (cv. 'Grand Rapids') por extratos aquosos de cinco espécies de Gleicheniaceae. Floresta e Ambiente, v.7, n.1, p.190-197, 2000.

SOUTO, X.C. et al. Comparative analysis of allelopathic effects produced by four foresty species during decomposition process in their soils in Galicia (NW. Spain). Journal of Chemical Ecology, v.20, n.11, p.3005-3015, 1994. Disponível em: <https:/ /commerce.metapress.com/content/w7n407541n377201/ resource-secured/?target=fulltext.pdf \&sid=wljft $1 \mathrm{mw}$ lknnxhua14o1le45\&sh=www.springerlink.com>. Acesso em: 20 jan. 2009. Doi: 10.1007/BF02098405.

SOUZA FILHO, A.P.S. et al. Potencial alelopático de Myrcia guianensis. Planta Daninha, v.24, n.4, p.649-656, 2006. Disponível em: <http://www.scielo.br/scielo.php?script=sci_arttext\&pid=S010083582006000400005\&lng=pt\&nrm=iso>. Acesso em: 20 jan. 2009. Doi: 10.1590/S0100-83582006000400005. 